\title{
Association of triiodothyronine levels with future development of metabolic syndrome in euthyroid middle-aged subjects: a 6-year retrospective longitudinal study
}

\author{
Hye Jeong Kim¹, , Ji Cheol Bae², Hyeong Kyu Park1, Dong Won Byun', Kyoil Suh', \\ Myung Hi Yoo', Jae Hwan Jee ${ }^{3}$, Jae Hyeon Kim4, Yong-Ki Min, Sun Wook Kim ${ }^{4}$ and \\ Jae Hoon Chung ${ }^{4}$ \\ 'Division of Endocrinology and Metabolism, Department of Internal Medicine, Soonchunhyang University Hospital, \\ Soonchunhyang University College of Medicine, Seoul, Korea, ${ }^{2}$ Division of Endocrinology and Metabolism, \\ Department of Medicine, Changwon Samsung Hospital, Sungkyunkwan University School of Medicine, Changwon, \\ Korea, ${ }^{3}$ Department of Health Promotion Center, Samsung Medical Center, Sungkyunkwan University School of \\ Medicine, Seoul, Korea, and ${ }^{4}$ Division of Endocrinology and Metabolism, Department of Medicine, Thyroid Center, \\ Samsung Medical Center, Sungkyunkwan University School of Medicine, Seoul, Korea \\ *(H J Kim and J C Bae contributed equally to this work)
}

Correspondence should be addressed to J H Chung

Email

thyroid@skku.edu

\begin{abstract}
Background: Several cross-sectional studies have reported that thyroid hormone levels are associated with cardiovascular risk markers and metabolic syndrome (MetS) even in euthyroid subjects. However, the prognostic role of serum thyroid hormone levels in the risk of incident Mets has not been elucidated.

Aim: We aimed to investigate the associations of baseline serum thyroid hormone levels with the development of MetS in healthy subjects.

Methods: This 6-year, cross-sectional, longitudinal and follow-up study was conducted in 12037 euthyroid middleaged subjects without MetS subjected to comprehensive health examinations. Subjects were grouped according to total triiodothyronine (T3) quartiles. The hazard ratio (HR) for the development of MetS according to T3 quartiles was estimated using Cox proportional hazards model.

Results: During the 6-year period, 3544 incident cases of MetS (29\%) were identified. The proportion of subjects with incident MetS increased across the T3 quartiles ( $P$ for trend $<0.001)$. The HR and $95 \%$ confidence interval $(\mathrm{Cl})$ for the development of MetS were significantly higher in the highest T3 quartile compared with the lowest T3 quartile even after adjusting for confounding variables including gender, age and smoking (HR: $1.238,95 \% \mathrm{Cl}: 1.128-1.358$, $P<0.001$ ).

Conclusion: In euthyroid middle-aged subjects, serum T3 levels are associated with increased risk for future development of MetS.
\end{abstract}

\section{Introduction}

Metabolic syndrome (MetS) is a complex disease characterized by several abnormalities including central obesity, glucose intolerance, hypertension and dyslipidemia $(1,2)$. MetS is considered the disease with the fastest growing incidence (3) and is the most
() 2017 European Society of Endocrinology Printed in Great Britain important disease worldwide because of the increased risk of cardiovascular morbidity and mortality $(4,5)$. To establish a better therapeutic and preventive strategy for MetS, a better understanding of its mechanisms is necessary. 
Thyroid disease is associated with atherosclerotic cardiovascular disease $(6,7)$. In addition, thyroid hormones have been reported to influence energy homeostasis (8), lipid and glucose metabolism $(9,10,11)$ and blood pressure (BP) (12). Therefore, the study of the association between serum thyroid hormone levels and components of MetS is essential.

Recently, several cross-sectional studies have reported that thyroid hormone levels are associated with MetS even in euthyroid subjects $(13,14,15,16,17,18,19,20,21$, $22,23,24,25)$. Serum thyroid-stimulating hormone (TSH) levels within the reference range have been positively associated with components of MetS $(19,20,21,22,23$, 24). Low normal free thyroxine (fT4) levels have been associated with MetS parameters (13, 14, 15, 16, 17, 18), whereas high normal total triiodothyronine (T3) or free triiodothyronine (fT3) levels have been positively correlated with components of MetS $(14,18,25)$. However, the prognostic role of serum thyroid hormone levels in the risk of incident MetS was not assessed in those crosssectional studies.

Herein, we aimed to investigate the associations of baseline serum thyroid hormone levels with the development of MetS in a large population of euthyroid subjects.

\section{Subjects and methods}

\section{Study population}

Middle-aged subjects between 35 and 65 years were tested by a comprehensive clinical examination, which is every once per year, at least more than four consecutive times within six years (between January 2006 and December 2012; $n=22$ 955) at the Health Promotion Center of Samsung Medical Center (Fig. 1). Among these subjects, 10918 were excluded for the following reasons, on the basis of the 2006 records: known cardiovascular disease including coronary heart disease and/or stroke $(n=567)$, subjects met the criteria for MetS $(n=3546)$, absence of data (questionnaire, anthropometric measurements, HbA1c, insulin, TSH, T3 and/or T4; $n=7531$ ), abnormal thyroid function (TSH, T3, and/or T4 below or above the normal reference range; $n=1992$ ), abnormal liver function (aspartate aminotransferase and/or alanine aminotransferase $\geq 2.5$ above the upper limit of normal; $n=101$ ) and/or abnormal kidney function (serum creatinine levels $>1.3 \mathrm{mg} / \mathrm{dL} ; n=75)$ ). Several subjects met more than two criteria. After exclusion of ineligible participants, 12037 subjects (6950 men

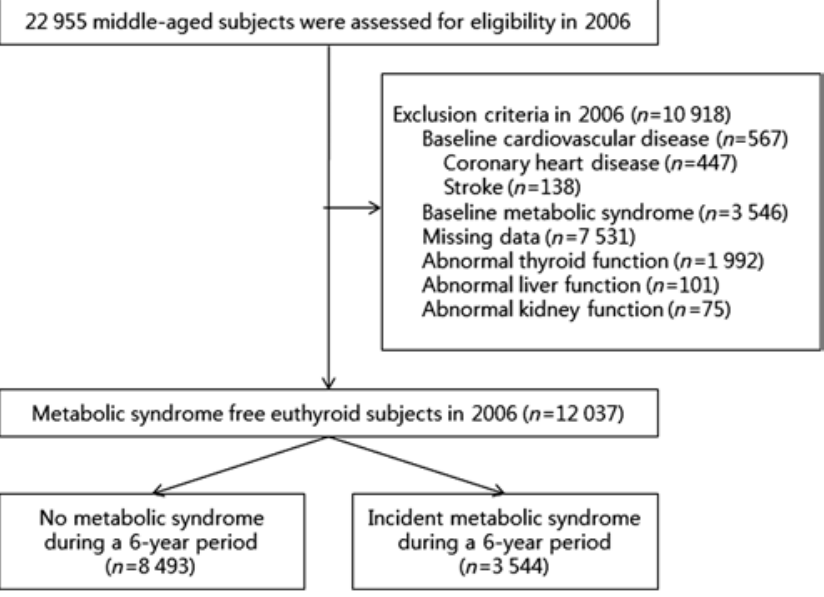

Figure 1

Flow chart of the study population.

and 5087 women with a mean age of 50.2 years) were deemed eligible and were included in the study. All data on anthropometric variables, laboratory tests, radiologic images and coded answers to self-report questionnaires were stored in an electronic medical record. Informed consent requirement for this study was waived by the institutional review board because researchers only accessed the database for analysis purposes, and personal identifying information was not accessed. The study protocol was approved by the Institutional Review Board at Samsung Medical Center.

\section{Definitions of euthyroidism}

Euthyroidism was defined as serum TSH (reference range: 0.4-5.0 U/L), T3 (reference range: 76-190 ng/dL) and T4 (reference range: $4.7-12.5 \mu \mathrm{g} / \mathrm{dL}$ ) levels within their normal reference range.

\section{Definitions of metabolic syndrome}

Considering a joint interim statement of the International Diabetes Federation (IDF), the American Heart Association/National Heart, Lung, and Blood Institute (AHA/NHLBI) criteria (26), American College of Endocrinology position statement (27) and our modifications, MetS was defined when three or more of the following criteria were met: (1) fasting glucose levels $\geq 100 \mathrm{mg} / \mathrm{dL}$ or participants were on antidiabetic treatment; (2) BMI $\geq 25 \mathrm{~kg} / \mathrm{m}^{2}$; (3) triglycerides (TG) levels $\geq 150 \mathrm{mg} / \mathrm{dL}$; (4) high-density lipoprotein (HDL) cholesterol levels $<40 \mathrm{mg} / \mathrm{dL}$ in men and $<50 \mathrm{mg} / \mathrm{dL}$ in 
women and (5) BP $\geq 130 / 85 \mathrm{mmHg}$ or participants were on antihypertensive treatment.

\section{Clinical and laboratory measurements}

The smoking status was assessed using a questionnaire completed during an interview and was classified as never smoker, former smoker or current smoker.

Height and weight were measured while subjects were wearing light clothing without shoes. BMI was calculated as weight in kilograms divided by height in meters squared $\left(\mathrm{kg} / \mathrm{m}^{2}\right)$. Percentage body fat and waistto-hip ratio were estimated using a multi-frequency bioimpedance analyzer (InBody 720, Biospace Co., Seoul, Korea) with eight-point tactile electrodes (2 electrodes for each foot and hand) and were validated for reproducibility and accuracy for body composition (28). BP was measured using an automatic manometer with the participants in a seated position after a 5-min resting period.

After overnight fasting, blood samples were collected from the antecubital vein into vacuum tubes and subsequently analyzed at a central, certified laboratory at Samsung Medical Center. Total cholesterol, low-density lipoprotein (LDL) cholesterol, HDL cholesterol and TG levels were measured with an enzymatic colorimetric method using a Modular D2400 analyzer (Roche Diagnostics). Blood glucose concentration was measured using a nonenzymatic method. HbA1c level was measured using an immunoturbidimetric assay with a Cobas Integra 800 automatic analyzer (Roche Diagnostics) and a reference value range of $4.4-6.4 \%$. HbA1c measurements were standardized with a reference method by following the standards of the Diabetes Control and Complications Trial (DCCT) and the

Table 1 Baseline characteristics of euthyroid subjects with respect to the development of metabolic syndrome during a 6-year period. Data are presented as weighted numbers (percentages) or means \pm S.D. as appropriate for the variable. Demographic and biochemical characteristics of the study population with respect to the development of metabolic syndrome were compared using an independent $t$-test for continuous variables and $\chi^{2}$ test for categorical variables.

\begin{tabular}{|c|c|c|c|c|}
\hline \multirow[b]{2}{*}{ Variables } & \multicolumn{3}{|c|}{ Incident metabolic syndrome } & \multirow[b]{2}{*}{ Overall $(n=12037)$} \\
\hline & No $(n=8493)$ & Yes $(n=3544)$ & $P$ value & \\
\hline Male & $4249(50 \%)$ & $2701(76 \%)$ & $<0.001$ & $6950(58 \%)$ \\
\hline Age (years) & $50.1 \pm 6.6$ & $51.3 \pm 6.1$ & $<0.001$ & $50.2 \pm 7.1$ \\
\hline Smoking (current/former/never) (\%) & $14 / 25 / 61$ & $25 / 37 / 38$ & $<0.001$ & $18 / 28 / 54$ \\
\hline BMI $\left(\mathrm{kg} / \mathrm{m}^{2}\right)$ & $22.8 \pm 2.3$ & $25.2 \pm 2.2$ & $<0.001$ & $23.4 \pm 2.6$ \\
\hline Overweight $(\mathrm{BMI} \leq 25-<30)$ & $1124(13 \%)$ & $1697(48 \%)$ & $<0.001$ & $2821(23 \%)$ \\
\hline Obesity (BMI $\geq 30)$ & $38(0.4 \%)$ & $101(2.8 \%)$ & $<0.001$ & $139(1.2 \%)$ \\
\hline \multicolumn{5}{|l|}{ Body fat (\%) } \\
\hline Male & $19.2 \pm 4.2$ & $21.7 \pm 4.2$ & $<0.001$ & $20.2 \pm 4.4$ \\
\hline Female & $26.9 \pm 5.3$ & $31.1 \pm 4.9$ & $<0.001$ & $27.6 \pm 5.4$ \\
\hline \multicolumn{5}{|l|}{ Waist-to-hip ratio } \\
\hline Male & $0.89 \pm 0.06$ & $0.91 \pm 0.06$ & $<0.001$ & $0.89 \pm 0.06$ \\
\hline Female & $0.84 \pm 0.06$ & $0.89 \pm 0.05$ & $<0.001$ & $0.85 \pm 0.06$ \\
\hline Systolic BP (mmHg) & $107.7 \pm 13.8$ & $114.3 \pm 13.6$ & $<0.001$ & $109.8 \pm 14.3$ \\
\hline Diastolic BP (mmHg) & $66.3 \pm 9.4$ & $71.1 \pm 9.2$ & $<0.001$ & $67.6 \pm 9.9$ \\
\hline Total cholesterol (mg/dL) & $186.7 \pm 30.7$ & $190.9 \pm 30.6$ & $<0.001$ & $187.7 \pm 30.7$ \\
\hline LDL cholesterol (mg/dL) & $121.1 \pm 27.7$ & $127.6 \pm 27.9$ & $<0.001$ & $122.5 \pm 28.0$ \\
\hline \multicolumn{5}{|l|}{ HDL cholesterol (mg/dL) } \\
\hline Male & $58.0 \pm 12.0$ & $51.6 \pm 10.6$ & $<0.001$ & $55.5 \pm 11.9$ \\
\hline Female & $66.4 \pm 13.7$ & $56.5 \pm 11.0$ & $<0.001$ & $64.8 \pm 13.8$ \\
\hline Triglycerides (mg/dL) & $103.7 \pm 50.4$ & $149.5 \pm 83.7$ & $<0.001$ & $114.3 \pm 63.7$ \\
\hline Fasting glucose (mg/dL) & $86.0 \pm 12.0$ & $92.1 \pm 15.4$ & $<0.001$ & $87.5 \pm 12.8$ \\
\hline $\mathrm{HbA1c}(\%)$ & $5.3 \pm 0.5$ & $5.5 \pm 0.6$ & $<0.001$ & $5.3 \pm 0.6$ \\
\hline HOMA-IR & $1.8 \pm 0.8$ & $2.2 \pm 1.0$ & $<0.001$ & $1.9 \pm 0.9$ \\
\hline TSH (U/L) & $2.4 \pm 1.3$ & $2.2 \pm 1.3$ & $<0.001$ & $2.3 \pm 1.3$ \\
\hline T3 (ng/dL) & $110.8 \pm 18.0$ & $113.5 \pm 18.7$ & $<0.001$ & $111.4 \pm 18.3$ \\
\hline $\mathrm{T} 4(\mu \mathrm{g} / \mathrm{dL})$ & $8.5 \pm 1.4$ & $8.5 \pm 1.4$ & NS & $8.4 \pm 1.4$ \\
\hline Follow-up duration (months) & $65.8 \pm 9.8$ & $67.2 \pm 8.7$ & $<0.001$ & $65.9 \pm 9.6$ \\
\hline
\end{tabular}

BMI, body mass index; BP, blood pressure; HDL, high-density lipoprotein; HOMA-IR, homeostasis model assessment of insulin resistance; LDL, low-density lipoprotein. 
National Glycohemoglobin Standardization Program (NGSP). Serum insulin concentration was measured using an immunoradiometric assay (TFB Co., Ltd, Tokyo, Japan). As a marker of insulin resistance, the homeostatic model assessment of insulin resistance (HOMA-IR) was calculated using the following formula: HOMA-IR $=($ fasting insulin $(\mu \mathrm{IU} / \mathrm{mL}) \times$ fasting glucose $(\mathrm{mmol} / \mathrm{L})) / 22.5$ (29). Serum TSH levels were measured using an immunoradiometric assay kit (Immunotech, Marseille Cedex, France). Serum T3 and T4 levels were measured using a radioimmunoassay kit (FT4 RIA KIT; Immunotech).

\section{Study design and statistical analysis}

All 12037 subjects were divided into two groups according to whether or not they developed MetS during a mean follow-up period of 65.9 months. In addition, all subjects were categorized into quartiles on the basis of their TSH and T3 levels using following reference ranges: (1) TSH (Q1: $0.4-1.4 \mathrm{U} / \mathrm{L} ; \mathrm{Q} 2: 1.5-2.0 \mathrm{U} / \mathrm{L}$; Q3: 2.1-3.0 U/L; and Q4: 3.1-5.0 U/L) and (2) T3 (Q1: 76-98 ng/dL; Q2: 99-110 ng/dL; Q3: 111-123 ng/dL; and Q4: $124-190 \mathrm{ng} / \mathrm{dL}$ ). Continuous variables are expressed as the mean \pm S.D. and categorical variables are expressed as percentage (\%). Clinical and laboratory data on the development of MetS were compared using an independent-sample Student's $t$-test for continuous variables and $\chi^{2}$ test for categorical variables. The characteristics of the study population according to the TSH and T3 quartiles were compared using one-way analysis of variance (ANOVA) for continuous variables and $\chi^{2}$ test for categorical variables. After adjusting for confounding variables, Cox proportional hazard regression analysis was used to estimate the hazard ratios (HR) for the development of MetS. Cumulative time-to-event curves were analyzed using the Kaplan-Meier method. All statistical tests were

Table 2 Clinical and biochemical characteristics of euthyroid subjects according to triiodothyronine quartiles. Data are presented as weighted numbers (percentages) or means \pm S.D. as appropriate for the variable. Demographic and biochemical characteristics were compared using an one-way analysis of variance (ANOVA) for continuous variables and $\chi^{2}$ test for categorical variables.

\begin{tabular}{|c|c|c|c|c|c|}
\hline \multirow[b]{2}{*}{ Variables } & \multicolumn{4}{|c|}{ T3 quartiles } & \multirow[b]{2}{*}{$P$ value } \\
\hline & $\begin{array}{c}\text { Q1 }(76-98 \mathrm{ng} / \mathrm{dL}) \\
\quad(n=3290)\end{array}$ & $\begin{array}{c}\text { Q2 (99-110 ng/dL) } \\
(n=3037)\end{array}$ & $\begin{array}{c}\text { Q3 }(111-123 n g / d L) \\
(n=2847)\end{array}$ & $\begin{array}{c}\text { Q4 }(124-190 \mathrm{ng} / \mathrm{dL}) \\
(n=2863)\end{array}$ & \\
\hline Male & $1689(51 \%)$ & $1708(56 \%)$ & $1714(60 \%)$ & $1839(64 \%)$ & $<0.001$ \\
\hline Age (years) & $50.1 \pm 6.6$ & $50.3 \pm 6.4$ & $50.7 \pm 6.4$ & $50.7 \pm 6.4$ & $<0.001$ \\
\hline Smoking (current/former/never) (\%) & $13 / 26 / 61$ & $16 / 28 / 56$ & $19 / 30 / 51$ & $23 / 30 / 47$ & $<0.001$ \\
\hline BMI $\left(\mathrm{kg} / \mathrm{m}^{2}\right)$ & $23.3 \pm 2.4$ & $23.5 \pm 2.6$ & $23.7 \pm 2.5$ & $23.7 \pm 2.5$ & $<0.001$ \\
\hline Overweight (BMI $\leq 25-<30)$ & $688(21 \%)$ & $705(23 \%)$ & $669(24 \%)$ & $759(27 \%)$ & $<0.001$ \\
\hline Obesity (BMI $\geq 30$ ) & $26(0.8 \%)$ & $40(1.3 \%)$ & $40(1.4 \%)$ & $33(1.2 \%)$ & NS \\
\hline \multicolumn{6}{|l|}{ Body fat $(\%)$} \\
\hline Male & $19.6 \pm 4.4$ & $20.0 \pm 4.4$ & $20.3 \pm 4.4$ & $20.7 \pm 4.3$ & $<0.001$ \\
\hline Female & $26.4 \pm 5.4$ & $27.5 \pm 5.2$ & $28.0 \pm 5.7$ & $28.9 \pm 5.1$ & $<0.001$ \\
\hline \multicolumn{6}{|l|}{ Waist-to-hip ratio } \\
\hline Male & $0.89 \pm 0.06$ & $0.89 \pm 0.06$ & $0.90 \pm 0.05$ & $0.90 \pm 0.06$ & 0.009 \\
\hline Female & $0.84 \pm 0.06$ & $0.85 \pm 0.06$ & $0.86 \pm 0.07$ & $0.86 \pm 0.06$ & $<0.001$ \\
\hline Systolic BP (mmHg) & $108.1 \pm 14.0$ & $109.0 \pm 14.0$ & $110.2 \pm 14.4$ & $111.7 \pm 14.0$ & $<0.001$ \\
\hline Diastolic BP (mmHg) & $66.6 \pm 9.7$ & $67.5 \pm 9.5$ & $68.1 \pm 9.6$ & $69.0 \pm 9.5$ & $<0.001$ \\
\hline Total cholesterol (mg/dL) & $177.4 \pm 28.8$ & $186.5 \pm 29.8$ & $192.0 \pm 30.3$ & $197.4 \pm 30.5$ & $<0.001$ \\
\hline LDL cholesterol (mg/dL) & $115.8 \pm 26.6$ & $122.2 \pm 27.5$ & $126.2 \pm 27.7$ & $129.0 \pm 28.1$ & $<0.001$ \\
\hline \multicolumn{6}{|l|}{ HDL cholesterol (mg/dL) } \\
\hline Male & $54.3 \pm 11.6$ & $55.0 \pm 11.4$ & $55.8 \pm 12.1$ & $56.8 \pm 12.4$ & $<0.001$ \\
\hline Female & $62.8 \pm 13.4$ & $64.7 \pm 13.7$ & $65.7 \pm 13.5$ & $67.1 \pm 14.2$ & $<0.001$ \\
\hline Triglycerides (mg/dL) & $102.5 \pm 51.6$ & $113.2 \pm 59.7$ & $122.5 \pm 62.0$ & $134.3 \pm 83.3$ & $<0.001$ \\
\hline Fasting glucose $(\mathrm{mg} / \mathrm{dL})$ & $87.4 \pm 15.1$ & $87.8 \pm 13.2$ & $87.8 \pm 12.1$ & $88.4 \pm 12.8$ & 0.001 \\
\hline $\operatorname{HbA} 1 \mathrm{c}(\%)$ & $5.3 \pm 0.6$ & $5.3 \pm 0.5$ & $5.3 \pm 0.5$ & $5.4 \pm 0.5$ & 0.002 \\
\hline HOMA-IR & $1.8 \pm 0.9$ & $1.9 \pm 0.9$ & $1.9 \pm 0.9$ & $2.0 \pm 0.9$ & $<0.001$ \\
\hline TSH (U/L) & $2.3 \pm 1.3$ & $2.3 \pm 1.3$ & $2.4 \pm 1.3$ & $2.4 \pm 1.3$ & NS \\
\hline $\mathrm{T} 4(\mu \mathrm{g} / \mathrm{dL})$ & $7.8 \pm 1.3$ & $8.3 \pm 1.3$ & $8.6 \pm 1.3$ & $9.1 \pm 1.3$ & $<0.001$ \\
\hline Follow-up duration (months) & $66.3 \pm 9.6$ & $66.4 \pm 9.4$ & $66.3 \pm 9.5$ & $65.9 \pm 9.6$ & NS \\
\hline
\end{tabular}


Table 3 Hazard ratio (HR) and 95\% confidence intervals (CI) for the development of metabolic syndrome among 12037 euthyroid subjects based on triiodothyronine quartiles during a 6-year period. HR and $95 \% \mathrm{Cl}$ for development of metabolic syndrome were estimated using Cox proportional hazard regression analysis. All $P$ values and $95 \% \mathrm{Cl}$ for $\mathrm{HR}$ were corrected by Bonferroni's method due to multiple testing.

\begin{tabular}{|c|c|c|c|c|}
\hline & \multicolumn{4}{|c|}{ T3 quartiles } \\
\hline & Q1 (76-98ng/dL) $(n=3290)$ & Q2 (99-110ng/dL) $(n=3037)$ & Q3 $(111-123 n g / d L)(n=2847)$ & Q4 $(124-190 \mathrm{ng} / \mathrm{dL})(n=2863)$ \\
\hline Incident of MetS (\%) & $844 / 3290(26 \%)$ & $858 / 3037(28 \%)$ & $872 / 2847(31 \%)$ & $970 / 2863(34 \%)$ \\
\hline Unadjusted & 1.000 & $1.111(1.010-1.221)^{\ddagger}$ & $1.233(1.121-1.355) *$ & $1.400(1.276-1.535) *$ \\
\hline Model 1 & 1.000 & $1.064(0.968-1.170)$ & $1.136(1.033-1.249)^{\dagger}$ & $1.266(1.154-1.389) *$ \\
\hline Model 2 & 1.000 & $1.056(0.960-1.162)$ & $1.120(1.018-1.231)^{\ddagger}$ & $1.238(1.128-1.358)^{*}$ \\
\hline
\end{tabular}

${ }^{\star} P<0.001,{ }^{\dagger} 0.001 \leq P<0.01,{ }^{\ddagger} 0.01 \leq P<0.05$.

MetS, metabolic syndrome; Model 1, adjusted for gender and age; Model 2, adjusted for gender, age and smoking; T3, triiodothyronine.

two-sided, and analyses were executed using SPSS for windows, version 14.0. A $P$ value of less than 0.05 was considered statistically significant.

\section{Results}

The baseline clinical and biochemical characteristics of 12037 subjects, including those who developed MetS during a 6-year period, are summarized in Table 1. Of these, 6950 subjects (58\%) were men, with a mean age of $50.2 \pm 7.1$ years at baseline. The serum TSH and T3 levels were $2.3 \pm 1.3 \mathrm{U} / \mathrm{L}$ and $111.4 \pm 18.3 \mathrm{ng} / \mathrm{dL}$ respectively. During the 6-year period, 3544 incident cases of MetS (29\%) were identified. Among them, 2701 (76\%) were men. The characteristics of the subjects with respect to the development of MetS are presented in Table 1. Subjects who subsequently developed MetS were more likely to be older and current or former smokers. They also had higher baseline values of BMI, body fat percentage, waist-to-hip ratio, systolic BP, diastolic BP, total cholesterol, LDL cholesterol, TG, fasting glucose, HOMA-IR and T3, but lower level of HDL cholesterol and TSH compared with those who did not develop MetS. There was no significant difference in T4 levels between the two groups.

We further explored clinical and biochemical characteristics at baseline according to TSH quartiles (Supplementary Table 1, see section on supplementary data given at the end of this article) and T3 quartiles (Table 2). As the TSH quartile increased, the proportion of men decreased, and subjects were more likely to be never smokers. Positive associations between TSH quartiles and total cholesterol were observed, whereas negative associations were observed between TSH quartiles and BMI, diastolic BP, fasting glucose and T4 levels. There were no significant differences between TSH quartiles and age, body fat percentage according to gender, waist-to-hip ratio according to gender, systolic BP, LDL cholesterol, HDL cholesterol according to gender, TG and T3. As the T3 quartile increased, the proportion of men increased, and subjects were more likely to be older and current or former smokers. Positive associations between T3 quartiles and BMI, body fat percentage, waist-to-hip ratio, systolic BP, diastolic BP, total cholesterol, LDL cholesterol, HDL cholesterol, TG, fasting glucose, HbA1c, HOMA-IR and $\mathrm{T} 4$ were observed. There were no significant differences between T3 quartiles and the levels of TSH.

The proportion of subjects with incident MetS decreased across the TSH quartiles (Supplementary Table 2, $P$ for trend <0.001). The HR of incident MetS significantly decreased as the TSH quartile increased. However, no associations were observed after additional adjustment for confounding variables including gender, age and smoking.

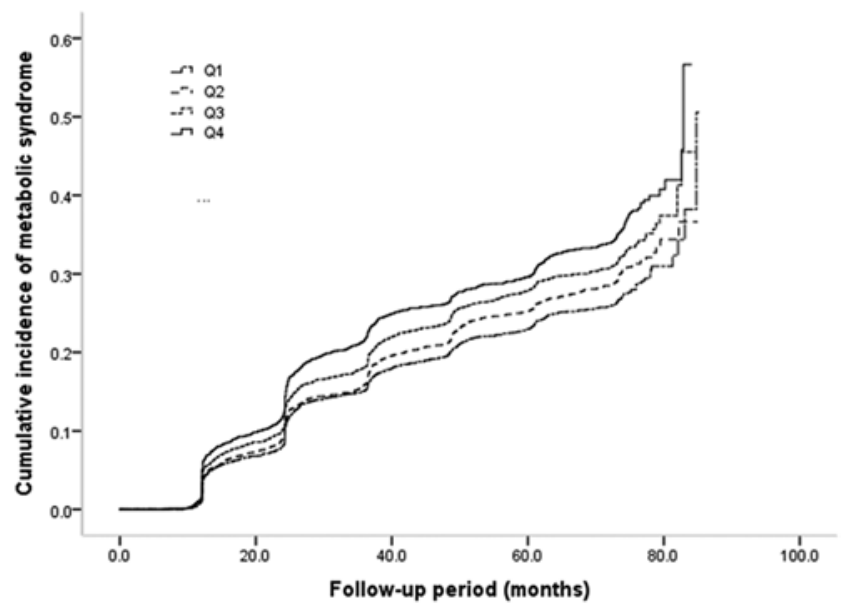

Figure 2

Kaplan-Meier plots showing a cumulative incidence of metabolic syndrome according to triiodothyronine quartiles during the follow-up period ( $P<0.001$ using the log-rank test). 
The proportion of subjects with incident MetS increased across the T3 quartiles (Table 3, P for trend $<0.001)$. Kaplan-Meier analysis showed a mean event period for MetS of 70.8 (95\% CI: 69.9-71.7), 69.6 (68.770.5), 67.6 (66.6-68.6) and 65.4 (64.4-66.4) months for subjects belonging to Q1, Q2, Q3 and Q4 respectively (Fig. 2, $P<0.001$ using the log-rank test). In a Cox proportional hazard model (Table 3 ), the HR of incident MetS significantly increased as the T3 quartile increased. Additional adjustment for confounding variables such as gender, age and smoking attenuated those effects. However, the highest T3 quartile continued to be a significant risk factor for developing MetS even after such adjustments (HR: 1.238, 95\% CI: 1.128-1.358, $P<0.001$ ).

\section{Discussion}

To the best of our knowledge, this is the first longitudinal observational study reporting an association between thyroid hormone levels and incident MetS in a healthy population. At baseline, subjects who subsequently developed MetS had unfavorable metabolic profiles and high T3 levels, compared with those who did not develop MetS. Higher T3 levels were strongly associated with unfavorable metabolic profile and increased risk of incident MetS in euthyroid middle-aged subjects during the 6-year period. In addition, we found an independently positive association between T3 levels and incident MetS even after adjusting for gender, age and smoking. On the other hand, we found no associations between serum TSH levels within reference range and risk of incident MetS despite the significant correlation between TSH levels and several metabolic parameters.

Recent cross-sectional studies have reported that T3 or fT3 levels were associated with various metabolic parameters in euthyroid individuals $(14,18,25,30,31$, 32, 33). T3 and/or fT3 levels had positive associations with body composition variables including BMI (14, 18, 25, $31,32,33)$, waist circumference $(14,18,31,32)$, waist-tohip ratio $(18,31)$, subcutaneous fat layer (31) and whole body and trunk fat mass $(25,33)$. We also observed strong positive associations between higher T3 levels and body fat parameters including BMI, body fat percentage and waist-to-hip ratio. Moreover, subjects who subsequently developed MetS had higher baseline T3 levels compared with those who did not develop MetS. Although the exact mechanisms underlying the association between thyroid hormones and unfavorable body composition or obesity are not clear, several mechanisms have been suggested. First, previous studies have suggested that leptin predominantly released by adipocytes could be a mediator. In the hypothalamus, leptin stimulates $T R H$ gene expression directly in the paraventricular nucleus (34, 35) and indirectly in the arcuate nucleus (34). In humans, leptin-stimulated TRH release increases circulating T3 and T4 concentrations, but not TSH concentrations (36). In mice, the thyroid gland expresses the long form of leptin receptors, and the administration of leptin to euthyroid animals increases circulating concentrations of T3 and T4 without affecting circulating concentrations of TSH $(37,38)$. Second, it has been suggested that changes in the activity of iodothyronine deiodinase lead to the conversion of T4 to T3. In addition, changes in type I deiodinase activity in white adipose tissue under the conditions of changing adiposity and the stimulatory effects of leptin on this activity were demonstrated in mice (39). Increases in type I deiodinase mRNA levels and enzyme activity in adipose tissue were documented in obese humans (40). However, no studies have reported changes in type II deiodinase activity in humans with increased adiposity. Third, a moderate increase in T3 and fT3 levels within the upper normal range in obesity may be regarded as an adaptation process for increased energy expenditure in response to increased body weight. Fasting and overfeeding studies on the role of thyroid hormones in the weight status showed that serum T3 concentrations decreased during fasting (41) and increased during overfeeding (42). In addition, T3 concentrations decreased after reducing overweight $(43,44,45)$.

Increase in cardiac output affects tissue oxygen consumption, blood volume, cardiac contractility and heart rate, which are mechanisms that may link T3 to BP (6). The administration of T3 has been shown to induce hypertension and myocardial hypertrophy in rats (46). Moreover, T3 is known to stimulate the activity of reninangiotensin systems $(47,48)$. Roef et al. (18) demonstrated that higher T3 and fT3 levels were associated with higher systolic and diastolic BP. Bakker et al. (49) revealed that serum fT3 levels in healthy euthyroid subjects correlated positively with systolic and diastolic BP, independent of age and gender. Therefore, our results on the positive association between $\mathrm{T} 3$ and systolic and diastolic BP in euthyroid subjects are consistent with those of previous studies $(18,25,49)$.

In the present study, subjects who subsequently developed MetS had higher baseline total cholesterol, LDL cholesterol and TG, but lower HDL cholesterol compared with those who did not develop MetS. On the other hand, positive associations between T3 quartiles and total 
cholesterol, LDL cholesterol, HDL cholesterol and TG were observed. Generally, the effects of thyroid hormones on lipid metabolism include enhanced utilization of lipid substrates, increased synthesis and mobilization of TG stored in adipose tissue, increased concentration of non-esterified fatty acids and increased lipoprotein-lipase activity (50). These findings are in contrast with our result on the relationship between T3 levels and lipid profiles. It is assumed that the association between T3 levels and lipid profiles is affected by gender, age, smoking status, body composition and insulin resistance.

Insulin resistance appears to be important to the pathophysiology of MetS (51) and has been reported to be associated with hyperthyroidism (52). In addition, it has been postulated that insulin sensitivity is regulated by thyroid hormones. The glucose transporter 2 and glucokinase play an important role as glucose sensors in pancreatic beta-cells (53) and the expression of glucose transporter 2 and glucokinase mRNA and protein can be modulated by $\mathrm{T} 3$ in pancreatic islets (54). In the context, the administration of T3 to healthy subjects resulted in insulin resistance (55). In addition, it has been reported that T3 may play a role in the regulation of insulin secretion, and in vitro studies using human and rat insulinoma cell lines showed that $\mathrm{T} 3$ promoted cell proliferation and protected cells from apoptosis in islet $\beta$-cell lines (56). Treatment of a human pancreatic duct cell line with T3-induced morphological and functional changes as indicated by a marked increase in insulin synthesis, transdifferentiation of this cell line into insulin-producing $\beta$-cells and upregulation of insulin and glucose transporter 2 mRNA levels (57). Ortega et al. (30) showed that fT3 levels were associated with insulin secretion independent of insulin sensitivity and glucose concentration in euthyroid individuals. In this study, we observed that higher T3 levels at baseline were associated with lower insulin sensitivity assessed by HOMA-IR and with higher fasting glucose levels in healthy euthyroid subjects. Our results are in agreement with those of Roef et al. (33) who noted that serum T3 and fT3 levels were positively associated with insulin and HOMA-IR levels. Lambadiari et al. also found a significant positive relationship of HOMA-IR and fT3 levels with early stages of type 2 diabetes after adjusting for age, gender and BMI in euthyroid subjects (52). Very recently, Roef et al. (18) showed that T3 and fT3 levels were positively associated with fasting glucose levels.

Therefore, strong associations have been found between T3 levels and several elements of MetS in healthy euthyroid subjects. The hazard ratio for MetS increased from the lowest to the highest quartiles of $\mathrm{T} 3$ even after adjusting for confounders. It is well known that the prevalence of MetS is higher in men than that in women (51) and the prevalence of thyroid dysfunction is higher in women than that in men (58). The prevalence of MetS increases with each decade of life and in parallel with the age-related increase in obesity (51). In addition, smoking is associated with both thyroid function and body composition. Because subjects who develop MetS in this study were predominantly men, older and current or former smokers, we adjusted for potential confounders including gender, age and smoking.

Some cross-sectional studies showed a positive relation between TSH levels within the reference range and prevalent MetS $(23,59)$, whereas others found no association (21). Conversely, we found that the proportion of subjects with incident MetS decreased across the TSH quartiles. Although HR of incident MetS significantly decreased as the TSH quartile increased, no associations were observed after additional adjustment for confounding variables including gender, age and smoking. The inconsistent results between TSH levels within the reference range and MetS may be due to differences in study populations, in the categorization of thyroid function, in the factors included for adjustments in the analyses and in cross-sectional or longitudinal approaches.

Few studies have evaluated the association between fT4 or T4 within the reference range and MetS or its parameters, and inverse associations between fT4 levels within reference range and metabolic parameters have been found $(13,16,18,21,31)$. Among these studies, two cross-sectional studies investigated the association of free T4 levels with MetS, and discordant results were found between studies. One study found an association between low normal fT4 levels and MetS (21), whereas another study did not (16). For T4, two studies identified positive associations between $\mathrm{T} 4$ levels within the reference range and metabolic profiles $(25,33)$. In the current study, data on fT4 levels were not available in most subjects, so we focused on T4 rather than fT4. Positive associations between T3 quartiles and T4 levels were observed.

The main limitation of our study is its retrospective nature. We did not measure anti-TPO antibodies to exclude potential underlying chronic autoimmune thyroid disease and disregarded information on other exposures, including alcohol intake and physical activity, which influence metabolic profiles. In addition, data on waist circumference in the assessment of obesity were not available. However, the availability of other 
anthropometric data, including BMI, percentage of body fat and waist-to-hip ratio, may overcome this limitation.

To date, no longitudinal study has evaluated the association between T3 levels and the development of MetS. A strength of our study involved analysis of data from 12037 consecutive subjects and the assessment of the development of MetS among euthyroid subjects during a 6-year period.

In conclusion, higher T3 levels were associated with increased risk of developing MetS in euthyroid middle-aged subjects. Further research on the potential mechanisms underlying the relationship between thyroid hormones and metabolic profiles may provide insights into the etiology of the MetS and help establish better therapeutic and preventive strategies.

\section{Supplementary data}

This is linked to the online version of the paper at http://dx.doi.org/10.1530/ EJE-16-0734.

\section{Declaration of interest}

The authors declare that there is no conflict of interest that could be perceived as prejudicing the impartiality of the research reported.

\section{Funding}

This study was supported by the Research Grant Number CB-2011-0302 of the Korean Foundation for Cancer Research and Soonchunhyang University Research Fund.

\section{References}

1 Reaven GM. Banting lecture 1988. Role of insulin resistance in human disease. Diabetes 198837 1595-1607. (doi:10.2337/ diab.37.12.1595)

2 Liese AD, Mayer-Davis EJ \& Haffner SM. Development of the multiple metabolic syndrome: an epidemiologic perspective. Epidemiologic Reviews 199820 157-172. (doi:10.1093/oxfordjournals.epirev. a017978)

3 Ford ES, Giles WH \& Mokdad AH. Increasing prevalence of the metabolic syndrome among U.S. adults. Diabetes Care 200427 2444-2449. (doi:10.2337/diacare.27.10.2444)

4 Isomaa B, Almgren P, Tuomi T, Forsen B, Lahti K, Nissen M, Taskinen MR \& Groop L. Cardiovascular morbidity and mortality associated with the metabolic syndrome. Diabetes Care 200124 683-689. (doi:10.2337/diacare.24.4.683)

5 Lakka HM, Laaksonen DE, Lakka TA, Niskanen LK, Kumpusalo E, Tuomilehto J \& Salonen JT. The metabolic syndrome and total and cardiovascular disease mortality in middle-aged men. JAMA 2002288 2709-2716. (doi:10.1001/jama.288.21.2709)

6 Klein I \& Ojamaa K. Thyroid hormone and the cardiovascular system. New England Journal of Medicine 2001344 501-509. (doi:10.1056/ NEJM200102153440707)

7 Cappola AR \& Ladenson PW. Hypothyroidism and atherosclerosis. Journal of Clinical Endocrinology and Metabolism 200388 2438-2444. (doi:10.1210/jc.2003-030398)
8 Krotkiewski M. Thyroid hormones in the pathogenesis and treatment of obesity. European Journal of Pharmacology 2002440 85-98. (doi:10.1016/S0014-2999(02)01420-6)

9 Kutty KM, Bryant DG \& Farid NR. Serum lipids in hypothyroidism-a re-evaluation. Journal of Clinical Endocrinology and Metabolism 197846 55-56. (doi:10.1210/jcem-46-1-55)

10 Chait A, Bierman EL \& Albers JJ. Regulatory role of triiodothyronine in the degradation of low density lipoprotein by cultured human skin fibroblasts. Journal of Clinical Endocrinology and Metabolism 197948 887-889. (doi:10.1210/jcem-48-5-887)

11 Torrance CJ, Devente JE, Jones JP \& Dohm GL. Effects of thyroid hormone on GLUT4 glucose transporter gene expression and NIDDM in rats. Endocrinology 1997138 1204-1214. (doi:10.1210/ endo.138.3.4981)

12 Fommei E \& Iervasi G. The role of thyroid hormone in blood pressure homeostasis: evidence from short-term hypothyroidism in humans. Journal of Clinical Endocrinology and Metabolism 200287 1996-2000. (doi:10.1210/jc.87.5.1996)

13 Lin SY, Wang YY, Liu PH, Lai WA \& Sheu WH. Lower serum free thyroxine levels are associated with metabolic syndrome in a Chinese population. Metabolism 200554 1524-1528. (doi:10.1016/j. metabol.2005.05.020)

14 De Pergola G, Ciampolillo A, Paolotti S, Trerotoli P \& Giorgino R. Free triiodothyronine and thyroid stimulating hormone are directly associated with waist circumference, independently of insulin resistance, metabolic parameters and blood pressure in overweight and obese women. Clinical Endocrinology 200767 265-269. (doi:10.1111/j.1365-2265.2007.02874.x)

15 Roos A, Bakker SJ, Links TP, Gans RO \& Wolffenbuttel BH. Thyroid function is associated with components of the metabolic syndrome in euthyroid subjects. Journal of Clinical Endocrinology and Metabolism 200792 491-496. (doi:10.1210/jc.2006-1718)

16 Kim BJ, Kim TY, Koh JM, Kim HK, Park JY, Lee KU, Shong YK \& Kim WB. Relationship between serum free T4 (FT4) levels and metabolic syndrome (MS) and its components in healthy euthyroid subjects. Clinical Endocrinology 200970 152-160. (doi:10.1111/j.13652265.2008.03304.x)

17 Garduno-Garcia Jde J, Alvirde-Garcia U, Lopez-Carrasco G, Padilla Mendoza ME, Mehta R, Arellano-Campos O, Choza R, Sauque L, Garay-Sevilla ME, Malacara JM et al. TSH and free thyroxine concentrations are associated with differing metabolic markers in euthyroid subjects. European Journal of Endocrinology 2010163 273-278. (doi:10.1530/EJE-10-0312)

18 Roef GL, Rietzschel ER, Van Daele CM, Taes YE, De Buyzere ML, Gillebert TC \& Kaufman JM. Triiodothyronine and free thyroxine levels are differentially associated with metabolic profile and adiposity-related cardiovascular risk markers in euthyroid middle-aged subjects. Thyroid 201424 223-231. (doi:10.1089/ thy.2013.0314)

19 Asvold BO, Bjoro T, Nilsen TI \& Vatten LJ. Association between blood pressure and serum thyroid-stimulating hormone concentration within the reference range: a population-based study. Journal of Clinical Endocrinology and Metabolism 200792 841-845. (doi:10.1210/ jc.2006-2208)

20 Asvold BO, Vatten LJ, Nilsen TI \& Bjoro T. The association between $\mathrm{TSH}$ within the reference range and serum lipid concentrations in a population-based study. The HUNT study. European Journal of Endocrinology 2007 156 181-186. (doi:10.1530/eje.1.02333)

21 Mehran L, Amouzegar A, Tohidi M, Moayedi M \& Azizi F. Serum free thyroxine concentration is associated with metabolic syndrome in euthyroid subjects. Thyroid 201424 1566-1574. (doi:10.1089/ thy.2014.0103)

22 Lai Y, Wang J, Jiang F, Wang B, Chen Y, Li M, Liu H, Li C, Xue H, $\mathrm{Li} \mathrm{N}$ et al. The relationship between serum thyrotropin and components of metabolic syndrome. Endocrine Journal 201158 23-30. (doi:10.1507/endocrj.K10E-272) 
23 Ruhla S, Weickert MO, Arafat AM, Osterhoff M, Isken F, Spranger J, Schofl C, Pfeiffer AF \& Mohlig M. A high normal TSH is associated with the metabolic syndrome. Clinical Endocrinology 201072 696-701. (doi:10.1111/j.1365-2265.2009.03698.x)

24 Wang F, Tan Y, Wang C, Zhang X, Zhao Y, Song X, Zhang B, Guan Q, $\mathrm{Xu} \mathrm{J}$, Zhang J et al. Thyroid-stimulating hormone levels within the reference range are associated with serum lipid profiles independent of thyroid hormones. Journal of Clinical Endocrinology and Metabolism 201297 2724-2731. (doi:10.1210/jc.2012-1133)

$25 \mathrm{Kim}$ HJ \& Bae JC. Triiodothyronine levels are independently associated with metabolic syndrome in euthyroid middleaged subjects. Endocrinology and Metabolism 201631 311-319. (doi:10.3803/EnM.2016.31.2.311)

26 Alberti KG, Eckel RH, Grundy SM, Zimmet PZ, Cleeman JI, Donato KA, Fruchart JC, James WP, Loria CM, Smith SC Jr et al. Harmonizing the metabolic syndrome: a joint interim statement of the International Diabetes Federation Task Force on Epidemiology and Prevention; National Heart, Lung, and Blood Institute; American Heart Association; World Heart Federation; International Atherosclerosis Society; and International Association for the Study of Obesity. Circulation 2009120 1640-1645. (doi:10.1161/ circulationaha.109.192644)

27 Einhorn D, Reaven GM, Cobin RH, Ford E, Ganda OP, Handelsman Y, Hellman R, Jellinger PS, Kendall D, Krauss RM et al. American College of Endocrinology position statement on the insulin resistance syndrome. Endocrine Practice 20039 237-252.

28 Malavolti M, Mussi C, Poli M, Fantuzzi AL, Salvioli G, Battistini N \& Bedogni G. Cross-calibration of eight-polar bioelectrical impedance analysis versus dual-energy $\mathrm{X}$-ray absorptiometry for the assessment of total and appendicular body composition in healthy subjects aged 21-82 years. Annals of Human Biology 200330 380-391. (doi:10.1080/ 0301446031000095211)

29 Matthews DR, Hosker JP, Rudenski AS, Naylor BA, Treacher DF \& Turner RC. Homeostasis model assessment: insulin resistance and beta-cell function from fasting plasma glucose and insulin concentrations in man. Diabetologia 198528 412-419. (doi:10.1007/ BF00280883)

30 Ortega E, Koska J, Pannacciulli N, Bunt JC \& Krakoff J. Free triiodothyronine plasma concentrations are positively associated with insulin secretion in euthyroid individuals. European Journal of Endocrinology 2008158 217-221. (doi:10.1530/EJE-07-0592)

31 Alevizaki M, Saltiki K, Voidonikola P, Mantzou E, Papamichael C \& Stamatelopoulos K. Free thyroxine is an independent predictor of subcutaneous fat in euthyroid individuals. European Journal of Endocrinology 2009161 459-465. (doi:10.1530/EJE-09-0441)

32 Kitahara CM, Platz EA, Ladenson PW, Mondul AM, Menke A \& Berrington de Gonzalez A. Body fatness and markers of thyroid function among U.S. men and women. PLoS ONE 20127 e34979. (doi:10.1371/journal.pone.0034979)

33 Roef G, Lapauw B, Goemaere S, Zmierczak HG, Toye K, Kaufman JM \& Taes Y. Body composition and metabolic parameters are associated with variation in thyroid hormone levels among euthyroid young men. European Journal of Endocrinology 2012167 719-726. (doi:10.1530/EJE-12-0447)

34 Ghamari-Langroudi M, Vella KR, Srisai D, Sugrue ML, Hollenberg AN \& Cone RD. Regulation of thyrotropin-releasing hormone-expressing neurons in paraventricular nucleus of the hypothalamus by signals of adiposity. Molecular Endocrinology 201024 2366-2381. (doi:10.1210/ me.2010-0203)

35 Perello M, Stuart RC \& Nillni EA. The role of intracerebroventricular administration of leptin in the stimulation of prothyrotropin releasing hormone neurons in the hypothalamic paraventricular nucleus. Endocrinology 2006147 3296-3306. (doi:10.1210/en.2005-1533)

36 Rosenbaum M, Goldsmith R, Bloomfield D, Magnano A, Weimer L, Heymsfield S, Gallagher D, Mayer L, Murphy E \& Leibel RL. Low-dose leptin reverses skeletal muscle, autonomic, and neuroendocrine adaptations to maintenance of reduced weight. Journal of Clinical Investigation 2005115 3579-3586. (doi:10.1172/JCI25977)

37 Teixeira CV, Ramos CD, Mouco T, Passos MC \& De Moura EG. Leptin injection during lactation alters thyroid function in adult rats. Hormone and Metabolic Research 200335 367-371. (doi:10.1055/s-2003-41359)

38 Nowak KW, Kaczmarek P, Mackowiak P, Ziolkowska A, Albertin G, Ginda WJ, Trejter M, Nussdorfer GG \& Malendowicz LK. Rat thyroid gland expresses the long form of leptin receptors, and leptin stimulates the function of the gland in euthyroid non-fasted animals. International Journal of Molecular Medicine 20029 31-34. (doi:10.3892/ ijmm.9.1.31)

39 Macek Jilkova Z, Pavelka S, Flachs P, Hensler M, Kus V \& Kopecky J. Modulation of type I iodothyronine 5 '-deiodinase activity in white adipose tissue by nutrition: possible involvement of leptin. Physiological Research 201059 561-569.

40 Ortega FJ, Jilkova ZM, Moreno-Navarrete JM, Pavelka S, RodriguezHermosa JI, Kopecky J \& Fernandez-Real JM. Type I iodothyronine 5 [prime]-deiodinase mRNA and activity is increased in adipose tissue of obese subjects. International Journal of Obesity 201236 320-324. (doi:10.1038/ijo.2011.101)

41 Spaulding SW, Chopra IJ, Sherwin RS \& Lyall SS. Effect of caloric restriction and dietary composition of serum $\mathrm{T} 3$ and reverse $\mathrm{T} 3$ in man. Journal of Clinical Endocrinology and Metabolism $1976 \mathbf{4 2}$ 197-200. (doi:10.1210/jcem-42-1-197)

42 Davidson MB \& Chopra IJ. Effect of carbohydrate and noncarbohydrate sources of calories on plasma 3,5,3'-triiodothyronine concentrations in man. Journal of Clinical Endocrinology and Metabolism 197948 577-581. (doi:10.1210/jcem-48-4-577)

43 Kiortsis DN, Durack I \& Turpin G. Effects of a low-calorie diet on resting metabolic rate and serum tri-iodothyronine levels in obese children. European Journal of Pediatrics 1999158 446-450. (doi:10.1007/s004310051117)

44 Reinehr T \& Andler W. Thyroid hormones before and after weight loss in obesity. Archives of Disease in Childhood 200287 320-323. (doi:10.1136/adc.87.4.320)

45 Reinehr T, Isa A, de Sousa G, Dieffenbach R \& Andler W. Thyroid hormones and their relation to weight status. Hormone Research 2008 70 51-57. (doi:10.1159/000129678)

46 Willard PW. L-Triiodothyronine and dinitrophenol-induced hypertension. Proceedings of The Society for Experimental Biology and Medicine 1969132 181-187. (doi:10.3181/00379727-132-34176)

47 Ichihara A, Kobori H, Miyashita Y, Hayashi M \& Saruta T. Differential effects of thyroid hormone on renin secretion, content, and mRNA in juxtaglomerular cells. American Journal of Physiology $1998 \mathbf{2 7 4}$ E224-E231.

48 Chan JS, Chan AH, Nie ZR, Sikstrom R, Lachance S, Hashimoto S \& Carriere S. Thyroid hormone, L-T3, stimulates the expression of the angiotensinogen gene in cultured opossum kidney (OK) cells. Journal of the American Society of Nephrology 19922 1360-1367.

49 Bakker SJ, ter Maaten JC, Popp-Snijders C, Heine RJ \& Gans RO. Triiodothyronine: a link between the insulin resistance syndrome and blood pressure? Journal of Hypertension 199917 1725-1730. (doi:10.1097/00004872-199917120-00009)

50 Pucci E, Chiovato L \& Pinchera A. Thyroid and lipid metabolism. International Journal of Obesity and Related Metabolic Disorders 200024 (Supplement 2) S109-S112. (doi:10.1038/sj.ijo.0801292)

51 Cornier MA, Dabelea D, Hernandez TL, Lindstrom RC, Steig AJ, Stob NR, Van Pelt RE, Wang H \& Eckel RH. The metabolic syndrome. Endocrine Reviews 200829 777-822. (doi:10.1210/ er.2008-0024)

52 Lambadiari V, Mitrou P, Maratou E, Raptis AE, Tountas N, Raptis SA \& Dimitriadis G. Thyroid hormones are positively associated with insulin resistance early in the development of type 2 diabetes. Endocrine 201139 28-32. (doi:10.1007/s12020-010-9408-3) 
53 Matschinsky FM. Glucokinase as glucose sensor and metabolic signal generator in pancreatic beta-cells and hepatocytes. Diabetes 199039 647-652. (doi:10.2337/diab.39.6.647)

54 Garcia-Flores M, Blazquez E \& Zueco JA. Effects of triiodothyronine and bovine growth hormone on glucose transporter isoform-2 (GLUT-2) and glucokinase (GK) gene expression in pancreatic islets of fetal and adult rats. Pflügers Archiv 2001442 662-667. (doi:10.1007/ s004240100583)

55 Dimitriadis G, Baker B, Marsh H, Mandarino L, Rizza R, Bergman R, Haymond M \& Gerich J. Effect of thyroid hormone excess on action, secretion, and metabolism of insulin in humans. American Journal of Physiology 1985248 E593-E601.

56 Verga Falzacappa C, Panacchia L, Bucci B, Stigliano A, Cavallo MG, Brunetti E, Toscano V \& Misiti S. 3,5,3'-Triiodothyronine (T3) is a survival factor for pancreatic beta-cells undergoing apoptosis. Journal of Cellular Physiology 2006206 309-321. (doi:10.1002/jcp.20460)
57 Misiti S, Anastasi E, Sciacchitano S, Verga Falzacappa C, Panacchia L, Bucci B, Khouri D, D'Acquarica I, Brunetti E, Di Mario U et al. 3,5,3'-Triiodo-1-thyronine enhances the differentiation of a human pancreatic duct cell line (hPANC-1) towards a beta-cellLike phenotype. Journal of Cellular Physiology 2005204 286-296. (doi:10.1002/jcp.20293)

58 Hollowell JG, Staehling NW, Flanders WD, Hannon WH, Gunter EW, Spencer CA \& Braverman LE. Serum TSH, T(4), and thyroid antibodies in the United States population (1988-1994): National Health and Nutrition Examination Survey (NHANES III). Journal of Clinical Endocrinology and Metabolism 200287 489-499. (doi:10.1210/ jcem.87.2.8182)

59 Lee YK, Kim JE, Oh HJ, Park KS, Kim SK, Park SW, Kim MJ \& Cho YW. Serum TSH level in healthy Koreans and the association of TSH with serum lipid concentration and metabolic syndrome. Korean Journal of Internal Medicine 201126 432-439. (doi:10.3904/kjim.2011.26.4.432)

Received 29 August 2016

Revised version received 20 December 2016

Accepted 17 January 2017 